\title{
Monseñor Romero y Medellín
}

\author{
Miguel Cavada Diez, \\ San Salvador.
}

El trigésimo aniversario de los documentos de Medellín nos ofrece la oportunidad de volver a las cuestiones fundamentales para la fe y la lglesia. En este artículo pretendemos mostrar la importancia que tuvo la enseñanza de Medellín para Monseñor Romero. Más que ofrecer nuestras propias reflexiones, nuestro objetivo es ofrecer la palabra profética de Monseñor Romero, esta vez, articulada con la palabra del magisterio de Medellín.

A nuestro juicio son tres los aporles que Monseñor Romero retoma de Medellín y que están muy presentes en su predicación. Primero, el discemimiento de la presencia del Dios de la liberación en la situación de miseria que viven las mayorías populares, miseria que es producto de una "injusticia que clama al cielo". El segundo aporte de Medellín que Monseñor Romero gusta destacar es que América Latina necesita cambios profundos y urgenles, pero no habrá un continente nuevo sin personas nuevas. Y finalmente, el tercer gran aporte que Monseñor Romero recoge de Medellín es la conversión de la Iglesia a los pobres. Para Monseñor Romero la opción preferencial por los pobres fue fundamental. Su misma persona se ha convertido en el símbolo de una Iglesia que se convierte a los pobres y desde ellos emprende su misión liberadora.

\section{Monseñor Romero y el magisterio de la Iglesia}

Medellín no significó lo mismo para Monseñor Romero antes y después de su conversión. No queremos con esto decir que Monseñor Romero rechazara las conclusiones de Medellín, pero es claro que tenía ciertos prejuicios, los cuales desaparecieron posteriormente. Antes de ser arzobispo de San Salvador, Monseñor Romero fue protagonista de diversos conflictos eclesiales, que tienen como denominador común los documentos de Medellín!. En estos conflictos Monse-

1. Cfr. Z. Diez y J. Macho, "En Santiago de Maria me topé con la pobreza". Dos años de la vida de Monseñor Romero (1975-1976) ¿Años de cambio?, San Salvador, 1994, pp. 117-120; J. R. Brockman, La palabra queda. Vida de Mons. Romero, San Salvador, 1985, pp. 69-71. 
ñor Romero acusa a sus oponentes de hacer una reducción e interpretación parcial de Medellín, pero detrás de esta acusación se esconde cierta reticencia a aceptar, en su conjunto, la novedad de Medellín. Según un testimonio, en los tiempos que era obispo de Santiago de María, Monseñor Romero citaba el Vaticano 11 , pero nunca a Medellín2.

Las dudas y prejuicios desaparecen una vez es arzobispo, y Monseñor Romero fue, a partir de entonces, un claro defensor de los documentos de Medellín. Como muestra de este cambio de actilud basta leer sus cartas pastorales? ${ }^{3}$.

Queremos hacer ver que la adhesión de Monseñor Romero al magisterio de Medellín y de la Iglesia en general no fue una adhesión meramente verbal. Monseñor Romero se esforzó por "hacer sangre y vida, verdad e historia" el magisterio de la Iglesia. Monseñor Romero no solamente transmitió la enseñanza, sino que encamó el magisterio de la Iglesia universal en la realidad concreta de El Salvador y denunció concretamente aquellas realidades que se oponían a dicho magisterio:

Es fácil predicar teóricamente sus enseñanzas. Seguir fielmente el magisterio del Papa en teoría es muy fácil. Pero cuando se trata de vivir, cuando se trata de encarnar, cuando se Irata de hacer realidad en la historia de un pueblo sufrido como el nuestro, esas enseñanzas salvadoras, es cuando surgen los conflictos. Y no es que me haya hecho infiel. ¡Jamás! Al contrario, siento que hoy soy más fiel porque vivo la prueba, el sufrimiento y la alegría íntima de proclamar, no solamente con palabras y con profesiones de labios, una doctrina que siempre he creído y amado, sino que estoy tratando de hacerla vida en esta comunidad que el Señor me ha encargado. Y yo les suplico a todos ustedes, queridos hermanos, que si de verdad somos calólicos, seguidores de un Evangelio auténtico, y por auténtico muy difícil, si de verdad queremos

2. Cfr. J. R. Brockman, op. cit., p. B5.

3. En la carta pastoral que escribió siendo obispo de Santiago de María, El Espiritu Santo en la Jglesia (1975) no cita a Medellín en ninguna ocasión. Dos años más tarde, en su primera carta pastoral como arzobispo de San Salvador, La lglesia de la pascua (abril, 1977) hace tres importantes citas de Medellín. En la scgunda carta pastoral como arzobispo de San Salvador, La Iglesia, cuerpo de Cristo en la historia (agosto, 1977), confirma el cambio de actitud respeclo al magisterio de Medcllín. Este texto es prueba de ello: “El Concilio Vaticano II y Medellín representan para nosotros, los cristianos de hoy, la actilud humilde y honrada de la Iglesia en su afán de ser el Cuerpo de Jesús en esta inleresante hora de la historia". La presencia de Medellin en su tercera carta pastoral, La Iglesia y las organizaciones poliricas populares (agoslo, 1978), es profusa. El capltulo dedicado a la violencia está inspirado claramente en Medellin. La cuarta carta pastoral, Misión de la lglesia en medio de la crisis del pals (agosto, 1979), lue escrila pocos meses despućs de rcalizarse la rcunión de Puebla, es natural que las citas a Medellin disminuyan dando paso a Puebla. En su conjunto, esta última carta pastoral es concebida como el momento de presentar los documentos de Puebla y aplicarlos a la rcalidad salvadoreña. 
hacer honor a esa palabra de seguidores de Cristo, no tengamos miedo de hacer sangre y vida, verdad e historia, esa doctrina que de las páginas del Evangelio se hacen actualidad en la doctrina de los concilios y de los papas, que tratan de vivir como verdaderos pastores las vicisiludes de su tiempo (Homilia 2 de julio de 1978, V, p. 42).

Esta encamación del magislerio causó el conflicto, sobre todo con aquellas personas y sectores de la sociedad y de la misma Iglesia que, por un parle, proclaman su adhesión al Papa y, a la vez, se oponen con todos sus medios y poder a la aplicación y vivencia de dicho magisterio:

Le dije al Santo Padre en Roma: Santo Padre, acatar las doctrinas de la Santa Sede, del magisterio, elogiarlas, alabarlas, defenderlas teóricamenie es muy fácil; pero cuando se trata de encarnar esa doctrina y hacerla vida en una diócesis, en una comunidad y señalar los hechos concretos que están contra esa doctrina, entonces surgen los conflictos (Homilia 16 de julio de 1978, V, p. 75).

Queremos poner un ejemplo de la notable diferencia que existe entre una adhesión verbal al magisterio de la Iglesia y realizar una encarnación profética de dicho magisterio, en la realidad concreta de cada país y de cada lglesia. Monseñor Romero cita el texto que Medellín dirige "a los que tienen una mayor participación en la riqueza, en la cultura o en el poder" (Medellín 2, 17) y lo hace en el contexlo de la reloma agraria que la Junta Revolucionaria de Gobierno de El Salvador trataba de impulsar en aquel tiempo. La cita del magisterio eclesial se actualiza en un llamado a la oligarquía a colaborar y no oponerse, mediante la violencia, a la reforma agraria. He aquí el texto:

También me quiero dirigir en este mornento $y$ en este asunto tan grave $y$ delicado a los sectores económicamente poderosos que van a ser afectados por la reforma agraria. Quiero dirigirme a ustedes, queridos hermanos, no como juez ni como enemigo, sino como pastor y como salvadoreño, hermano de todos los salvadoreños. Me interesa invitarlos a que caigan en la cuenta de la responsabilidad tan grande que tienen en estos momentos de colaborar a que la crisis económica, política y social del país sea superada sin acudir a la violencia. Esas demostraciones de tiroteos y, sobre todo, el temor que se tiene - - i es que no es verdad- de que la derecha está ingresando armas al país y va a pagar mercenarios. No es así como se defiende un bieneslar. Quiero recordarles lo que Medellín dice a este respecto: "Si se retienen celosamente sus privilegios $y$, sobre todo, los defienden empleando ustedes mismos medios violentos, se hacen responsabies ante la historia de provocar 'las revoluciones explosivas de la desesperación' — son todavía palabras de Medellín dirigiéndose a la oligarquía-. De su aclitud depende, pues, en gran parte el porvenir pacífico de los países de América Latina" (Medellín 2, 17). A través del clamor del pueblo salvadoreño, a través del 
intento de reforma agraria, a través de estos signos de los tiempos, Dios les está llamando como ha llamado este domingo por la voz de Juan Bautista: "El que tiene dos túnicas que dé al que no tiene, y el que tiene de comer que dé al que no tiene" (Homilía 16 de diciembre de 1979, VIII, pp. 56-57).

Este es un claro ejemplo de la aplicación de un texto del magisterio de la Iglesia a la situación concreta y a los destinatarios para quienes fue escrito. Si necesario es aceplar y esludiar el magisterio de la Iglesia, más necesario es emplearlo cuando las situaciones de la realidad lo exigen. $Y$ es lo que hizo Monseñor Romero. Y esto es lo que hizo a Monseñor Romero un profela y un mártir. De modo que Monseñor Romero se convierte en un modelo de lo que debe hacer la Iglesia con su magisterio.

Nadie podrá reprochar a Monseñor Romero que su predicación no tiene la solidez que da el magisterio de la Iglesia. Pocos obispos hay que utilicen el magisterio de la Iglesia en sus predicaciones con la insistencia y profundidad con la que lo hizo Monseñor Romero. Sus homilías están repletas de continuas referencias y citas del magisterio de la Iglesia, citas que encama oportuna y proféticamente. Monseñor Romero no recurre al magisterio de la Iglesia solamente para educar la fe de sus oyentes, sino para transformar y llamar a la conversión.

Esto, sin duda, dio credibilidad a la Iglesia, pero a la vez fue motivo de muchos conflictos. Aun a pesar de la presión por dar "marcha atrás", Monseñor Romero "no volvió la vista atrás", precisamente, porque estaba convencido4 de que no seguía su propio capricho, sino que los conflictos le vinieron por su fidelidad al magisterio.

El mal sería que pase con el documento de Puebla lo mismo que pasó con Medellín: que muchos, llevados por los prejuicios, a veces por la ignorancia, no lo pusieron en práctica. Si nuestra arquidiócesis se ha convertido en una diócesis conflictiva, no les quepa duda, es por su deseo de fidelidad a esta evangelización nueva, que del Concilio Vaticano Il para acá y en las reuniones de obispos latinoamericanos, están exigiendo que tiene que ser una evangelización muy comprometida, sin miedo (Homilia 11 de marzo de 1979, VI, p. 191).

Monseñor Romero, en repelidas ocasiones, reivindicó que su predicación y la pastoral de la arquidiócesis estaba en comunión con el Papa y con el cuerpo episcopal latinoamericano y tenía el respaldo del magisterio de la Iglesia5. Mon-

4. "Muchos andan diciendo que yo soy presionado y que estoy predicando cosas que yo no creo. Hablo con convicción; sé que les estoy diciendo la palabra de Dios. He confrontado su palabra y con el magisterio, y creo en mi conciencia que voy bien" (Homilla 15 de mayo de 1977, I-II, p. 5I).

5. Cfr. Homilias 8 de mayo de 1977, J-II, p. 29; 15 de mayo de 1977, J-II, p. 52; 5 de junio de 1977, I-II, p. 82; 9 de octubre de 1977, I-II, p. 264; 25 de diciembre de 1977, III, p. 95; 1 de enero de 1978, III, p. 119; 5 de marzo de 1978, IV, p. 57; 9 de 
señor Romero afirmó, en reiteradas ocasiones, que la arquidiócesis es ficl a los lineamientos del magisterio de la Iglesia universal y de Medellín en particular. Lo expresó en el primer año de su labor pastoral arquidiocesana:

La línea que estamos siguiendo en el arzobispado no es un capricho ni un lavado de cerebro, como muchos dicen; simplemente es tralar de ponernos en la línea del Vaticano Il y Medellin, que son pautas autorizadas y que el Papa ratifica en la Evangelii Nuntiandi (Homilia 21 de agosto de 1977, I-II, p. 183).

Y lo expresó de forma más categórica y profética en su última homilía, en catedral6:

Ya sé que hay muchos que se escandalizan de estas palabras y quieren acusarla de que ha dejado la predicación del evangelio para melerse en política; pero no acepto yo esta acusación, sino que hago un esfuerzo para que todo lo que nos ha querido impulsar el Concilio Vaticano II, la reunión de Medellín y de Puebla, no sólo lo tengamos en las páginas y lo estudiemos teóricamente, sino que lo vivamos y lo traduzcamos en esta conflictiva realidad de predicar como se debe el Evangelio para nuestro pueblo. Por eso le pido al Señor, durante loda la semana, mientras voy recogiendo el clamor del pueblo y el dolor de tanto crimen, la ignominia de tanta violencia, que me dé la palabra oportuna para consolar, para denunciar, para llamar al arrepentimiento, y aunque siga siendo una voz que clama en el desierlo, sé que la lglesia está haciendo el esfuerzo por cumplir su misión (Homilia 23 de marzo de 1980, VIII, p. 359).

Si esta fue la actitud de Monseñor Romero frente al magisterio de la Iglesia, veamos qué dice en concreto de Medellín. En primer lugar, pide que se lean y estudien sus documentos, y se queja de que muchos conozcan a Medellín solamente a través de artículos periodísticos tendenciosos:

También les anuncio la publicación, ya está en circulación, de los documentos de Medellín, que es un esfuerzo de la Universidad Centroamericana José Simeón Cañas para poner al alcance de nuestro pueblo esos documentos que ningún calólico de hoy debe desconocer. Es una lástima que muchos están conociendo esos documentos a través de anteojos falsos, vidrios que distor-

abril de 1978, IV, p. 145; 2 de julio de 1978, V, pp. 42 y 49; 16 de julio de 1978, V, p. $75 ; 1$ de octubre de 1978, V, p. 216; 31 de diciembre de 1978, VI, p. 90; 21 de eлero de 1979, VI, p. 129; 11 de marzo de 1979, VI, pp. 190-191; 22 de abril de 1979, Vl, pp. 319-320; 13 de mayo de 1979, VI, pp. 335-336; 29 de julio de 1979, VII, p. 128; 26 de agosto de 1979, VIJ, p. 207; 16 de septiembre de 1979, VII, pp. 253-254; 23 de sepliembre de 1979, VII, p. 275; 30 de sepliembre de 1979, VII, p. 309; 16 de diciembre de 1979, VIII, p. 53; 6 de cnero de 1980, VIII, Pp. 123-124; 2 de marzo de 1980, VIII, p. 299.

6. En semejantes términos se expresó en la Homilia del 2 de sepliembre de 1979, VII, p. 218. 
sionan son esas publicaciones tendenciosas, dispuestas a que el mundo crea que la Iglesia es marxista, y muchos no conocen los documentos de Medellín más que a través de esas columnas venenosas... $Y$ así, pues se trata de que estos documentos de Medellín hay que conocerlos en su propia fuente. Ya están a la mano esas fuentes (Homilía 14 de agosto de 1977, I-II, p. 171).

La publicación a la que Monseñor Romero se refiere fue editada en 1977, es decir, nueve años después de haberse realizado la reunión de Medellín. Dada la trascendencia del documento, son muchos años de silencio. Monsenor Romero felicitó a los padres jesuitas por dicha iniciativa editorial7 y se alegró porque el pueblo tendría la oportunidad de conocer directamente las conclusiones de Medellín.

En segundo lugar, Monseñor Romero pide que "no dudemos de los documentos del Vaticano II ni de Medellin; son documentos de la Iglesia"8:

Cuando mencionamos los documentos de Medellín muchas gentes se asustan, pero es porque no los saben leer. Medellín es el pensamiento de la Iglesia para el continente latinoamericano. Naturalmente que muchos han abusado de esos documentos, así como olros también los consideran como un tabú de miedo. No es otra cosa que la inspiración cristiana a los pueblos latinoamericanos (Homilia 22 de enero de 1978, 111, p. 157).

Y finalmente, Monseñor Romero defiende los documentos de Medellín de los ataques de sus detractores. Los sectores conservadores de la sociedad salvadoreña no vieron con buenos ojos los documentos de Medellín. En los medios de comunicación social, sobre todo, la prensa escrila, eran frecuentes las columnas donde acusaban a la Iglesia de abandonar su misión religiosa. Monseñor Romero sale al paso de tales acusaciones:

Ya no es tiempo de estar confundiendo, por ejemplo, los documentos de Medellín con el marxismo. Ahí está saliendo en un periódico de la ciudad una columna venenosa, en que está tratando de interprelar Medellín con calegorías marxistas; eso es pura calumnia. Medellín fue una reunión de obispos de América, autorizada por el Papa, en 1968, para traer a este continente la doctrina del Concilio Vaticano II... Me acuerdo que Monseñor Pironio, un santo obispo, decía: "Ha sido un soplo del Espíritu sobre nuestro continente". Pero si no se le conoce, si se le quiere presentar con afán de calumniar a la lglesia, asi se explica, pues, que a Medellín se le llame subversivo (Homilía 22 de mayo de 1977, 1-II, pp. 60-61).

7. Cfr. Carta de Monseñor Romero al director de UCA Editores. Archivo del Centro Pastoral Monseñor Romero, Universidad Centroamericana José Simeón Cañas.

8. Homilia IS de mayo de 1977, I-11, p. 51. 
Si impactante fue lo que dijo Medellín, no menos impacto luvo el cómo lo dijo. Medellín, retomando la inspiración del Vaticano II, no hace magisterio a partir del magisterio, sino a partir de la realidad latinoamericana. Es el método teológico conocido con el esquema ver-juzgar-actuar. Medellín se toma en serio la realidad de América Latina, discieme en ella los signos de los liempos, es decir, las interpelaciones de Dios mismo, encamado en la historia; a esta primera palabra de Dios desde la vida y la realidad, se une la luz de la Escritura y del magisterio universal de la Iglesia y, finalmente, se extraen unos compromisos eclesiales y pastorales.

Pues bien, no es otro el método que Monseñor Romero utilizó en sus homilías dominicales?. Monseñor Romero supo captar de Medellín no solamente el mensaje, sino también el método teológico y pastoral. Las homilías de Monseñor Romero parten de la realidad salvadoreña. Monseñor Romero no predica sino de lo que ha "vislo" durante la semana y desde esa realidad, acompañada con la palabra de la sagrada escritura y el magisterio eclesial, eleva su voz reclamando la justicia y la vida para los pobres y llamando incansablemente a la conversión. Sus homilías terminan por donde comienzan, la realidad misma que ahora quiere ver transformada, la realidad en todas sus dimensiones: personal, social, política, económica y cultural. Si la palabra de Monseñor Romero era esperada, escuchada y comprendida por el pueblo no es porque, como él mismo decía, estuviera hablando de las "estrellas" 10 , sino porque estaba hablando de y desde los problemas reales que sufría el pueblo, y porque Monseñor Romero veía en esos acontecimientos la presencia de Dios que interpela y llama a la conversión y al seguimiento de Jesús.

\section{Medellín y la realidad salvadoreña}

Medellín fue una buena noticia para los pobres de América Latina, buena noticia porque anima a la verdadera liberación, y también buena noticia por lo sorprendenle e inesperado. ¿Quién pudo preveer que Medellín se convertiría en el "pentecostés" de la Iglesia latinoamericana? Lo mismo podemos decir de Monseñor Romero, su persona y su mensaje fueron buena noticia para los pobres, porque les dio y les da esperanza de liberación, pero fue una buena noticia aun mayor por lo que tuvo de inesperada. ¿Quién iba a pensar que aquel Monseñor Romero que aceptaba, no sin reticencias y temores, los documentos de Medellín, sería profela y mártir por hacer realidad lo que Medellín dijo? Quizá no hubiese existido un Monseñor Romero de no haberse dado el inesperado acontecimiento de Medellín y quizá también Medellín no hubiera pasado de ser un documento

9. Cfr. M. Cavada Diez, "Predicación y profecia. Análisis de las homilias de Monseñor Komero", Revista Latinoamericana de Teologia 34 (1995) pp. 4-8.

10. Cfr. Homilia 4 de diciembre de 1977, III, p. 19. 
escrito de no haber existido personas, como Monseñor Romero, que lo hicieron "sangre y vida, verdad e historia".

En este apartado vamos a estudiar qué aportes de Medellín retomó Monseñor Romero con más frecuencia en sus homilías dominicales para iluminar la realidad salvadoreña y transmilir su mensaje profélico.

\subsection{La violencia institucionalizada}

El primer gesto profético de Medellín consistió, como ya hemos dicho, en abrir los ojos a la realidad y reconocer, en la miseria de las muchedumbres de pobres, el principal signo de los tiempos. La miseria y la pobreza de las mayorías son, a la vez, un pecado socialıl, y un signo de los liempos, desde el cual Dios cuestiona al mundo y a la Iglesia. Monseñor Romero se convierte a los pobres en la medida en que abre sus ojos y su corazón a la tremenda realidad de pobreza y muerte que lo rodea. A partir de entonces, para Monseñor Romero, no hay otra cosa: todo lo analiza, denuncia, anima o discierne desde el Dios que vive en los pobres. Y desde esta opción por los pobres es que tanto Medellín como Monseñor Romero nos ofrecen su magisterio y su profecía:

Las masas de miseria, dijeron los obispos de Medellín, son un pecado, una injusticia que clama al cielo. La marginación, el hambre, el analfabetismo, la desnutrición y tantas otras cosas miserables que se entran por todos los poros de nuestro ser, son consecuencia del pecado, del pecado de aquellos que to acumulan todo y no tienen para los demás; y también del pecado de los que no teniendo nada, no luchan por su promoción; son conformistas, haraganes, no luchan por promoverse. Pero muchas veces no luchan, no por su culpa; es que hay una serie de condicionamientos, de estructuras, que no los dejan progresar. Es un conjunto, pues, de pecado mutuo. Y de ese pecado, que Medellín llama injusticia institucionalizada, injusticia hecha ambiente, de allí derivan esas situaciones que las lecturas de hoy nos las plastifican en la figura del leproso de Siria, que llega a buscar redención junto a un profela de Dios. Y en la angustia de diez leprosos que gritan a Cristo: "Señor, ten piedad de nosotros", en esos enfermos cabe mirar hoy esa muchedumbre lánguida que grita desde su marginación, una liberación que no les llega de ninguna parle, dicen los documentos de Medellín (Homilia 9 de oclubre de 1977, I-II, pp. 266-267).

Dado que a Monseñor Romero le tocó predicar en un momento histórico convulsionado por la violencia y con la grave amenaza de una guerra civil, es natural que los textos de Medellín que reflexionan sobre la violencia le fueran de gran ayuda. De hecho, son los lextos que más cila. Los capítulos Justicia y Paz

11. Cfr. Homilia 11 de sepliembre de 1977, 1-JI, p. 212. 
inspiraron a Monseñor Romero para redactar su análisis y juicio sobre la violencia en El Salvador, en su tercera carta pastoral.

Monseñor Romero no escamoleó el hecho de la violencia. Bien pudo "dar un rodeo" para ahorrarse complicaciones y malentendidos a la hora de abordar una realidad tan espinosa. No elude el tema, al contrario, se enfrenta a él con clarividencia y valentia, y lo hace desde la perspectiva de las víctimas, desde las mayorías populares, organizadas y no organizadas, que en aquel entonces eran reprimidas a fuerza de balas. Monseñor Romero tipifica los diversos tipos de violencia y los juzga desde la fe y el magisterio. Para ello se auxilió de los documentos de MedeIlín. Monseñor Romero quiere ir a la raíz del mal, lo que Medellín llamó "violencia institucionalizada", la injusticia social:

La forma más aguda que presenta la violencia en nuestro continente y también en nuestro país, es la que llamaron los obispos en Medellín "violencia institucionalizada" (Paz, 16), produclo de una siluación de injusticia en la que la mayoría de los hombres y de las mujeres - sobre todo los niños - en nuestro país se ven privados de lo necesario para vivir. Se expresa esta violencia en la organización y en el funcionamiento diario de una sistema socio-económico y político que acepta como normal y corriente que el progreso no es posible sino mediante la utilización de las mayorías como fuerza productiva manejada por una minoría privilegiada. Encontraremos históricamente esta clase de violencia siempre que la maquinaria institucional de la vida social funcione en beneficio de una minoría o sistemáticamente discrimine a los grupos o personas que defiendan el verdadero bien común 12 .

La predicación de la Iglesia tiene que ser fuerte ante la violencia institucionalizada:

La Iglesia jamás predica el odio. La Iglesia siempre predica el amor. Y la lglesia, cuando reclama lo que llamó la asamblea episcopal de Medellín "la violencia institucionalizada", tiene que gritar violenta como los profetas, cuando violentos gritaban contra el orden injusto de su tiempo. No es que la Iglesia predique violencia, sino que han provocado otros la violencia, el odio, la tortura, el dolor, la desigualdad social, y la Iglesia tiene que ser fuerte en su lenguaje, porque es el de Cristo, que sin odio ni venganza, quiere arrancar del reino del pecado a las almas, para ponerlas en el reino de Dios (Homilía 6 de agosto de 1977, I-II, pp. 155-156).

Monseñor Romero denunció la absolutización del poder y del dinero como los causantes de la pobreza y la muerte. Para Monseñor Romero la violencia

12. La Iglesia y las organizaciones politicas populares. Tercera Carta Pastoral de Monseñor Osear A. Romero, Arzobispo de San Salvador y Primera de Monseñor Arturo Rivera Damas, Obispo de Santiago de María, 1978. 
institucionalizada no es un concepto abstracto, es la violencia de aquellas personas, grupos e instituciones que hacen del poder y de la riqueza ídolos intocables, que para mantenerse sacrifican a víctimas inocentes:

Son palabras de la Santa Sede. No son palabas demagógicas del obispo de San Salvador. No son palabras subversivas de los obispos del continente en Medellín. Lo que hicieron los obipos en Medellín es darle un nombre a esto que acaba de describir la palabra de la Santa Sede. Los obispos en Medellín dijeron: existe una injusticia, una violencia institucionalizada, una afán... un frenesí de mantener el poder, de mantener la economía y son capaces, en ese afán de mantenerse, de atropellar vidas y la sociedad enlera. Esta es violencia, la violencia institucionalizada (Homilia 13 de noviembre de 1977, I-II, p. 315).

Monseñor Romero recurre, asimismo, a Medellín para reflexionar sobre el derecho del pueblo a un insurrección en caso de una tiranía prologanda y evidente:

El documento de Medellín sobre la paz, citando un texto de la encíclica Populorum progressio de Pablo Vl, - hay dos grandes respaldos, pues, el Papa y los obispos de América Latina-, mencionan la legitimidad de una insurrección en el caso muy excepcional de tiranía evidente y prolongada que atentase gravemente a los derechos fundamentales de la persona y damnificase peligrosamente el bien común del país, ya provenga de una persona, ya de estructuras evidentemente injustas. Este es el principio. Pero inmediatamente tengamos en cuenta las condiciones. Advierte también la Iglesia el peligro de engendrar con ello nuevas violencias, nuevas injusticias, nuevas nuinas, lo cual haría también condenable el derecho de insurrección. Me van a decir usledes: "pues dice y no dice". Dice claramente, pero pone las condiciones de la verdadera moral. Y eso es lo difícil (Homilía 17 de septiembre de 1978, V, p. 194).

En el contexto del asesinato del P. Rafael Palacios, Monseñor Romero, cita a Medellín para señalar que el sacerdote asesinado es víctima de una estructura de pecado:

¿Por qué una extrema derecha tiene que cobrarse en un sacerdote el supuesto pecado de una extrema izquierda? Esta estructura es pecamiosa; este mirar a los hombres del país polarizados en derecha y en izquierda, nos lleva a entender que hay una crisis muy grave de estructura en nuestro país. Una estructura de pecado, como lo dijeron los obispos de Medellín, una estructura de violencia, que mientras no se cambie, seguirá cobrando víctimas, ya sea de la izquerda o de la derecha (Homilia 21 de junio de 1979, VII, p. 8). 
Superar esta estructura de pecado es condición para obtener la paz:

En Medellín, los obispos de América Latina —aprobados por el mismo Papa- dijeron que la paz en el continente no será posible mientras no se construya un orden más justo, que la paz no es ausencia de guerra, la paz no es miedo de represión, la paz no es equilibrio de dos poderes que se tienen pavor. La paz es fruto de la juslicia, la paz será flor de un amor y de una justicia en el ambiente (Homilía 6 de enero de 1978, III, p. 134).

\section{2. Converslón de las personas y las estructuras}

Uno de los texlos de Medellín predilectos de Monseñor Romero es aquel que se refiere a un cambio de corazones y estructuras 13 . Ni Medellín ni la teología de la liberación han marginado el aspecto personal de la liberación. Su énfasis ha consistido en ponerlas en relación. No es que una sea primera que la otra, sino que ambas, para ser auténticas, se necesitan. Monseñor Romero insistió a tiempo y a destiempo en la responsabilidad y la conversión personal del pecado; pero no hablaba de ésta aisladamente, sino en relación al aspecto social del pecado y de la liberación. El pensamiento de Monseñor Romero se puede resumir así: la liberación será tanto más auténtica y radical cuanto provenga de personas renovadas. Ni más ni menos que lo que dijo Medellín:

Yo quisiera, queridos hermanos, como fruto de esta reflexión en vísperas del día de la patria, recordarles lo que la Iglesia enseña: que las estructuras sociales, el pecado institucional en que vivimos, hay que cambiarlo. Todo esto liene que cambiar. Esto no puede seguir así. Todos los atropellos que mencioné al principio. Cambian de nombre las víctimas, pero la causa es la misma. Vivimos una situación de desigualdad, de injusticia, de pecado; y no es el remedio reprimir con las fuerzas de las amas, pagar para matar la voz que habla. Eso no remedia nada; empeora, hace florecer más el grito profético de la Iglesia. Lo que funciona es ponerse a cambiar desde la posición de cada uno, del gobiemo, del capital, del obrero, del mozo de trabajo, del propietario de fincas: más justicia, más amor. Pero, como no bastará el cambio de estructuras, dice Medellín: "Mientras no tengamos hombre nuevos, no tendremos continente nuevo". Mientras no tengamos salvadoreños nuevos, no tendremos una patria mejor, libre, verdaderamente independiente; porque la verdadera esclavitud está allí en el corazón del salvadoreño. Atado al pecado, no puede ser un agente de liberación (Homilia 11 de septiembre de 1977, I-Il, pp. 217-218).

El mismo texto es citado para argumentar que son las personas nuevas quienes deben emprender los cambios que la sociedad necesita:

13. "No tendremos un continente nucvo sin nuevas y renovadas estructuras; sobre todo, no habra continente nuevo sin hombres nuevos" (Medellin 1, 3). 
$Y$ hermanos, piensen bien, precisamente cuando un mundo necesita reivindicaciones sociales y políticas, cuando necesitamos cambios profundos y audaces, ¿quién los va a hacer? Medellín lo dice claro: los "hombres nuevos". Los hombres nuevos, renovados en esa conversión. Los enquistados en los viejos sistemas, caducos, los que quieren conservar a fuerza de represión y crimenes y pecado una situación que no se puede sostener, no van a renovar el mundo. Asi no se renueva. Es necesario que políticos y no políticos, gente de poder y gente del pueblo, todos tratemos de renovarnos en esa conversión interior... Por eso, antes que la renovación de estructuras, o mejor dicho, junto con la renovación de estructuras: renovación de corazones (Homilia 20 de agosto de 1978, V, pp. 139-140).

Un mes después, Monseñor Romero insiste en el tema:

Una liberación que se olvidara de Dios, al que hay que buscar; una liberación que no tuviera en cuenta liberarse del pecado, no sería la liberación de Dios. Y de nada serviría, dicen los obispos de Medellín -para que vean que no somos comunistas, de nada serviría cambiar estructuras, gobiernos, situaciones, mientras no se cambie el corazón del hombre. ¿De qué sirve manejar estrucluras nuevas con corazón egoísta? (Homilía 24 de septiembre de 1978, V, p. 209).

El mismo texto de Medellín es citado en otras homillas14. Además de los textos mencionados, Monseñor Romero cita ocasionalmente los capílulos de Medellín que hablan sobre la educación's y sobre la familia16 y la pastoral de élites, en este caso, para dirigirse a los militares 17.

\subsection{La opción por los pobres y la Iglesia de los pobres}

Gustavo Gutiérnez señala que la opción por los pobres es el aporte más importante de la vida y reflexión de la Iglesia en América Latina 18. Aunque la expresión "opción preferencial por los pobres" no aparece hasta los documentos de Puebla19, es Medellín quien inicia este movimiento de conversión de la lglesia a los pobres, como los mismos obispos lo reconocen en la reunión de Pueblazo. El capítulo La pobreza de la Iglesia marcó la vida eclesial a partir de 1968.

14. Cfr. Homilias 3 de diciembre de 1978, VI, p. 16, y 16 de diciembre de 1979, VII, p. 47.

15. Cfr. Homilia 22 de enero de 1978, IIl, p. 157.

16. Cfr. Homilla 31 de diciembre de 1978, VI, pp. 82-83.

17. Cfr. Homilla 4 de noviembre de 1979, VIl, pp. $405-406$.

18. Cfr. G. Gutiérrez, "Renovar la opción por los pobres", Revista Latinoamericana de Teologia 36 (1995) p. 269.

19. Cfr. Puebla 1134-1165.

20. "Volvemos a tomar, con renovada esperanza en la fuerza vivificante del Espírilu, la posición de la II Conferencia General que hizo una clara y profética opción preferencial y solidaria por los pobres" (Puebla 1134). 
Este capítulo inspiró y animó la pastoral y la predicación profética de Monseñor Romero y es lo que queremos mostrar ahora. Monseñor Romero vivió con fidelidad e intensidad el espíritu de Medellín, hizo de la opción por los pobres un asunto fundamental en su vida y convirtió la Iglesia arquidiocesana en una Iglesia de los pobres.

Como una muestra de la importancia que este capítulo de Medellín tuvo para Monseñor Romero no hay más que fijarse en la homilía que él mismo tituló "La pobreza de las bienaventuranzas, fuerza de verdadera liberación del pueblo"21. Monseñor Romero prepara los tres pensamientos de su conocido guión homilético22 a partir los documentos de Medellin que dintingue la pobreza como una denuncia, una espiritualidad y un compromiso (Medellín 14, 4)23.

Los pobres ocupan un puesto privilegiado en las homilías de Monseñor Romero, ellos son los protagonistas en todas las predicaciones, desde la primera hasta la última homilía:

Los pobres han marcado el verdadero caminar de la Iglesia. Una Iglesia que no se une a los pobres para denunciar desde los pobres las injusticias que con ellos se cometen no es verdadera Iglesia de Jesucristo (Homilía 17 de febrero de 1980, VIII, p. 233).

Monseñor Romero fundamenta la opción preferencial por los pobres en Dios mismo:

El Dios de los cristianos no tiene que ser otro, es el Dios de Jesucristo, el del que se identificó con los pobres, el del que dio su vida por los demás, el Dios que mandó a su Hijo Jesucristo a tomar una preferencia sin ambigüedades por los pobres (Homilla 27 de mayo de 1979, VI. p. 365).

Es muy útil e importante percatarse en qué contexto habla Monseñor Romero de la opción preferencial por los pobres. Monseñor no solamente habla de esta opción cuando quiere reclamar mayor solidaridad y compromiso con los pobres, sino cuando quiere reclamar una fe más auténtica en sus oyentes. $Y$ es muy significativo que cuando está explicando un concepto tan abstracto como es la trascendencia, hable de la opción preferencial por los pobres. Porque la justificación de esta opción no es puramente humana, sino teológica: hay que amar como Dios ama y hay que ver en los pobres no un estorbo, sino a "Cristo presente en los pequeñitos". Esto es para Monseñor Romero la transcendecia, esto es "evangelio puro":

21. Homilia 17 de febrero de 1980, VIII, pp. 229-253.

22. Cfr. M. Cavada Diez, op. cir., pp. 4-6.

23. Cfr. M. Cavada Diez, "La predicación como prolongación del proyecto salvífico de Cristo en las homilias de Monseñor Romero", Revista Latinoamericona de Teología, 38 (1996), pp. 111-117.

$$
R 20328
$$


Y volvemos aquí a la opción preferencial por los pobres. No es demagogia, es evangelio puro. Si no nos preocupamos de los intereses del pobrecito, del pequeñuelo, pero no de cualquier modo, sino porque representa a Jesús, por la fe que abre el humilde, el marginado, el pobre, el enfermo. Mirar en él a Jesús, esa es la transcendencia. Cuando no se mira más que un rival, un imprudente, alguien que viene a aguarme mis fiestas, naturalmente, el pobre estorba. Pero cuando se abraza, como abrazó Cristo al leproso, y cuando levanta el buen samaritano al herido, porque lo que haga a él, se lo hace a Cristo, ésta es la transcendencia, sin la cual no es posible una perspectiva de justicia social, Cristo presente en los pequeñitos (Homilia 30 de septiembre de 1979, VII, p. 314). Cristo:

La cercanía y solidaridad con los pobres nos permite conocer el misterio de

Queremos una Iglesia que de veras esté codo a codo con el pobre pueblo de El Salvador y así notamos que cada vez, en este acercarse al pobre, descubrimos el verdadero rostro del Siervo sufriente de Yahvé. Es allí donde nosotros conocemos más cerca el misterio de Cristo que se hace hombre y se hace pobre por nosotros (Homilía 17 de febrero de 1980, VIII, p. 234).

Para Monseñor Romero "es inconcebible que se diga a alguien 'cristiano' y no tome, como Cristo, una opción preferencial por los pobres"24. El escándalo no consiste en que la Iglesia opte por los pobres, sino justamente en lo contrario25. Monseñor Romero se alegra porque esta opción es la causa de la persecución de la Iglesia26.

Los textos que podríamos citar son incontables. Nos vamos a ceñir en esta ocasión a destacar algunos donde Monseñor Romero expone algo que fue fundamental en su eclesiología: el distanciamiento con los poderosos, y, posteriormente, citaremos aquellos otros en donde textualmente habla de la Iglesia de los pobres. Para Monseñor Romero la lglesia se convierte en una Iglesia de los pobres cuando se distancia de los poderosos y de los privilegios que éstos ofrecen:

Ahora la Iglesia no se apoya en ningún poder, en ningún dinero. Hoy la Iglesia es pobre. Hoy la Iglesia sabe que los poderosos la rechazan, pero que la

24. Homilla 9 de septicmbre de 1979, VII, p. 236. En términos pareciđos sc expresa también en otra homilia: "El cristiano que no quiere vivir ese compromiso de solidaridad con el pobre, no es digno de llamarse cristiano" (Homilia 17 de febrero de 1980, VIII, p. 240).

25. "Es un escándalo en nuestro ambiente... que haya personas e instituciones en la Iglesio que se despreocupen del pobre" (Homilla 1 de julio de 1979, VIl, p. 47).

26. "Me alegro hermanos que nuestra Iglesia sea perseguida precisamente por su opción preíerencial por los pobres y por tratar de encarnarse en el interés de los pobres" (Homilía 15 de julio de 1979, VII, p. 79). 
aman los que sienten en Dios su confianza... Esta es la Iglesia que yo quiero. Una Iglesia que no cuente con los privilegios y las valías de las cosas de la tierra. Una Iglesia cada vez más desligada de las cosas terrenas, humanas, para poderlas juzgar con mayor libertad desde su perspectiva del Evangelio, desde su pobreza (Homilia 28 de agosto de 1977, I-II, p. 200).

Monseñor Romero afirma que la Iglesia no debe ser "instrumento del poder", lamenta que la lglesia "haya caído en ese pecado" y declara que "no queremos ser juguete de los poderes de la tierra, sino que queremos ser Iglesia que lleva el evangelio auténtico"27. "La Iglesia no está para congraciarse con los grandes del mundo"28. La fortaleza de la Iglesia no le proviene del apoyo de los poderosos 29 , sino del seguimiento de Cristo crucificado:

Esta es la verdadera pobreza de la lglesia, ésta que yo les he tratado de predicar, queridos hermanos. Pobreza que hace consistir su fuerza en su propia debilidad, en su propio pecado; pero apoyado en la misericordia de Cristo, el poder del Señor. Esta Iglesia que no quiere hacer consistir su fortaleza en el apoyo de los poderosos o de la política, sino que se desprende con nobleza para caminar únicamente cogida de los brazos del crucificado, que es su verdadera fortaleza (Homilia 9 de julio de 1978, V, p. 62).

Para Monseñor Romero, una Iglesia que convoca multiludes en torno al culto y al templo, no es el criterio evangélico para juzgar su autenticidad:

Hermanos, no contemos la lglesia por la cantidad de gente, ni contemos la lglesia por sus edificios materiales. La Iglesia ha construido muchos templos, muchos seminarios, muchos edificios; las paredes materiales ahi se quedan, en la historia. Lo que importa son ustedes, los hombres, los corazones, la gracia de Dios dándoles la verdad y la vida de Dios. No se cuenten por muchedumbres; cuéntense por la sinceridad del corazón con que siguen esa verdad y esa gracia de nuestro Divino Redentor (Homilía 19 de diciembre de 1977, III, pp. 84-85).

La Iglesia de los pobres es una Iglesia donde florecen las comunidades eclesiales de base 30 :

Pienso en este instante en esta comunidad arquidiocesana, peregrina en estos cuatro departamentos, tan bonita, tan encantadora en sus comunidades de

27. Homilla 27 de noviembre de 1977, III, p. 6.

28. Homilla 30 de julio de $1978, \mathrm{~V}$, p. 97.

29. "No es un prestigio para la Iglesia estar bien con los poderosos. Este es el prestigio de la Iglesia: sentir que los pobres la sienten como suya, sentir que la lglesia vive una dimensión en la tierra llamando a todos, también a los ricos, a convertirse y salvarse desde el mundo de los pobres, porque ellos son únicamente los bienaventurados" (Homilia 17 de febrero de 1980, VIII, p. 239).

30. Cfr. Homilia 10 de sepliembre de 1978, V, p. 180. 
base, donde los hombres, los jóvenes, las mujeres, se conocen cada vez más íntimamente y sienten que en su corazón que los une está el amor del Padre, la gracia del Hijo y la comunión del Espíritu Santo. Por eso insisto tanto, queridos hermanos, que haya más y más comunidades de base. No es un invento de nuestros tiempos, es la gran necesidad de que los hombres cristianos se conozcan, se amen, vivan juntos concientizándose en esa energía divina (Homilía 21 de mayo de 1978, IV, p. 259).

A pesar de los malentendidos que pudiera ocasionar, Monseñor Romero no rehuyó utilizar la expresión "Iglesia de los pobres". Es frecuente en sus homilias. En casi todos los textos que siguen, Monseñor Romero cuando habla de la Iglesia de los pobres, habla también de los ricos, no para condenarlos, sino para llamarlos a la conversión; conversión que significa dar la espalda a los ídolos del poder y del dinero, y conversión que implica el desprendimiento de las riquezas para compartirlas con los pobres. Pero Monseñor Romero es insistente para decir que su criterio no es sociológico ni mucho menos marxista, sino teológico. La lglesia tiene que ser pobre y de los pobres, porque Jesús fue pobre y vino a dar la buena noticia de la liberación a los pobres.

La primera ocasión en que Monseñor Romero utiliza la expresión lglesia de los pobres es en septiembre de 1977. En esta ocasión, Monseñor Romero distingue la "pobreza pecadora" de la "pobreza digna". La primera es fruto del "desorden", deshumaniza a las personas, las toma conformistas y alienadas; la segunda es la pobreza del que toma conciencia de que es pobre por causa de la injusticia y lucha por superar esa injusticia, es la pobreza con espíritu, "es la pobreza que va a salvar al mundo". La cita es extensa, pero merece la pena transcribirla por completo:

Cuando la Iglesia se llama Iglesia de los pobres, no es porque esté consintiendo esa pobreza pecadora. La Iglesia se acerca al pecador pobre para decirle: conviértete, promuévele, no te adormezcas. Y esta misión de promoción, que la Iglesia está llevando a cabo, también estorba. Porque a muchos les conviene tener masas adomecidas, hombres que no despierten, gente conformista, satisfecha con las bellotas de los cerdos. La Iglesia no está de acuerdo con esa pobreza pecadora. Sí quiere la pobreza. Pero la pobreza digna, la pobreza que es fruto de una injusticia y lucha por superarse, la pobreza digna del hogar de Nazaret. José y María eran pobres, pero qué pobreza más santa, qué pobreza más digna. Gracias a Dios tenemos pobres también de esta categoría entre nosolros. Y desde esta categoría de pobres dignos, pobres sanlos, proclama Cristo: bienaventurados los que tienen hambre, bienaventurados los que lloran, bienaventurados los que tienen sed de justicia. Desde allí clama la Iglesia también, siguiendo el ejemplo de Cristo, que es esa pobreza la que va a salvar al mundo. Porque ricos y pobres tienen que hacerse pobres desde la pobreza evangélica, no desde la pobreza que es fruto del desorden y del vicio; 
sino desde la pobreza que es desprendimiento, que es esperarlo todo de Dios, que es voltearle la espalda al becerro de oro para adorar al único Dios, que es compartir la felicidad de tener con todos los que no tienen, que es la alegría de amar (Homilia 11 de septiembre de 1977, 1-II, p. 216).

Construir una Iglesia pobre y de los pobres, como enseñó Medellín, es motivo de tensiones y calumnias. Monseñor Romero fue acusado de dividir y polarizar a la Iglesia. A esto responde:

Aquí nos está dando Cristo la respuesta a una calumnia que se oye muy frecuente: ¿Por qué la Iglesia sólo le está predicando a los pobres? ¿Por qué la Iglesia de los pobres? ¿Qué acaso los ricos no tenemos alma? Claro que sí y los amamos entrañablemente y deseamos que se salven, que no vayan a perecer aprisionados en su propia idolatría, les pedimos espiritualizarse31, hacerse almas de pobres, sentir la necesidad, la angustia del necesitado $(\mathrm{Ho}-$ milía 15 de octubre de 1978, V, p. 250).

Las palabras de Monseñor Romero nos cuestionan e interpelan, como el siguiente fragmento, que aunque es una cita extensa, no queremos pasar por alto:

El bienestar de la Iglesia trae relajamiento. Los sacerdotes que se sienten bien en sus parroquias, jmucho cuidado! Los cristianos que sienten que el evangelio no les molesta, ;mucho cuidado! A este bienestar del culto sin compromiso se refiere la profecía tremenda de Malaquías: "Ahora os toca a vosotros, sacerdotes. Os apartasteis del camino, habéis hecho tropezar a muchos en la ley. Yo os haré despreciables, viles ante el pueblo". No hay cosa peor que un mal sacerdote. Si la sal se vuelve insípida, para qué sirve; ya - decía Crislonada más para echarla al suelo y que la pise la gente. ¿Qué triste es la palabra del sacerdote cuando ha perdido la credibilidad! Lata que suena. "No haber guardado mis caminos. Os fijáis en las personas al aplicar la ley". Si es don fulanito, si es doña fulana, con mucho gusto. Si es un pobrecito despreciable, ni caso se le hace. La Iglesia de los pobres es un criterio de autenticidad porque no es una Iglesia clasista. No quiere decir desprecio a los ricos, sino pedirle a los ricos que si no se hacen como pobres en el corazón no podrán entrar en el reino de los cielos. El verdadero predicador de Cristo es Iglesia de los pobres para encontrar en la pobreza, en la miseria,

31. Monseñor Romero pide a los ricos que se espirilualicen. El término es ambigüo, pues puede entenderse que es posible espiritualizarse sin renunciar a la posesión de las riquezas. Para disipar dudas, podemos comparer esta exprcsión con otro texto de Monseñor Romero: "Y a los ricos les quicro decir también que no basta una pobreza espiritual, una especie de deseo pero sin eficacia: mientras no encarnen esos deseos de pobreza evangélica en realizaciones que se interesen como en su propia causa por los pobres, como si se tratara de Cristo, seguirân siendo los ricos: "los que Dios desprecia', porque ponen más confianza en su dinero" (Homilia 1 de julio de 1979, VII, p. 49). 
en la esperanza del que reza en tugurio, en el dolor, en el no ser oído, un Dios que oye. "Os fijáis en las personas al aplicar la ley". ¿Qué bien lo decía el campesino: la ley es como la culebra, sólo muerde a los que andan descalzos! (Homilia 5 de noviembre de 1978, V, p. 275).

Monseñor Romero nos dice que la Iglesia de los pobres es la Iglesia que como Jesús anuncia la buena noticia a los pobres:

Cuando hablamos de la Iglesia de los pobres no estamos haciendo una dialéclica marxista, como si la otra fuera la lglesia de los ricos. Lo que estamos diciendo es que Crislo, inspirado en el espíritu de Dios, dijo: "Me ha enviado el Señor a evangelizar a los pobres" — palabras de la Biblia-, para decir que, para escucharlo, es necesario hacerse pobre (Homilia 3 de diciembre de 1978, VI, p. 11).

La razón de la Iglesia de los pobres está en Jesús:

La Iglesia se predica desde los pobres y no nos avergonzamos nunca de decir Iglesio de los pobres, porque entre los pobres quiso poner Cristo su cátedra: de redención (Homilia 24 de diciembre de 1978, VI, 76).

La lglesia de los pobres no es rechazo de los ricos, sino llamamiento a su conversión:

Cuando decimos Iglesia de los pobres simplemente estamos diciendo a los ricos también: vuelvan sus ojos a esta Iglesia y preocúpense de los pobres como de un asunto propio (Homilía 4 de marzo de 1979, VI, p. 183).

Esta misma preocupación reaparece en el texio siguiente:

Cuando la Iglesia se proclama la Iglesia de los pobres, como que se parcializa y desprecia a los ricos. ¡De ninguna manera! El mensaje es universal. Dios quiere salvar a los ricos también, pero precisamente porque los quiere salvar, les dice que no se pueden salvar mientras no se conviertan al Cristo que vive precisamente en los pobres (Homilia 1 de julio de 1979, VIl, p. 49).

En el texto que sigue, Monseñor Romero no acepla que haya dos Iglesias. Cuando él habla de la Iglesia de los pobres no está aceptando que haya una Iglesia de los ricos. Para Monseñor Romero es impensable una Iglesia de los ricos, porque cuando éslos están de rodillas ante los ídolos del poder y del dinero, no son cristianos - Monseñor Romero lo repite dos veces en el textoy mucho menos son Iglesia. "No hay más que una Iglesia", que está llamada a ser Iglesia de los pobres:

El otro día, a uno de estos hombres que proclaman la liberación en el sentido político, le preguntábamos: ¿Qué significa para ustedes la Iglesia? $Y$ dice esta palabra escandalosa: "Es que hay dos Iglesias: la Iglesia de los ricos y la Iglesia de los pobres. Creemos en la Iglesia de los pobres, pero no creemos 
en la Iglesia de los ricos". Naturalmente, es una frase demagógica y yo no admitiré nunca una división de la Iglesia. No hay más que una Iglesia, ésta que Cristo predica, la Iglesia que debe darse con todo el corazón; porque aquel que se llama católico y está adorando sus riquezas y no quiere desprenderse de ellas, no es cristiano, no ha compredido el llamamiento del Señor, no es Iglesia. El rico que está de rodillas ante su dinero, aunque vaya a misa y aunque haga actos piadosos, si no se ha desprendido en el corazón del ídolo dinero, es un idólatra, no es un cristiano. No hay más que una Iglesia, la que adora al verdadero Dios y la que le sabe dar a las cosas su valor relativo (Homilia 11 de noviembre de 1979, Vll, p. 426).

El último texto en que Monseñor Romero utiliza la expresión Iglesia de los pobres procede de una homilía de apenas un mes antes de su martirio y se constituye como una especie de testamento para todas aquellas personas creyentes que en Monseñor Romero encuentran ánimo e inspiración:

En el afán de hacer una Iglesia así, como la que nos ha presentado Cristo hoy: una Iglesia de los pobres, pero no por clase social, sino porque salva a través de los pobres a todo el que quiera salvarse. Tratemos de hacerla, hernanos, así, nuestra arquidiócesis (Homilía 17 de febrero de 1980, VIIl, p. 242).

Todos estos textos que hemos citado son de Monseñor Romero. Es decir, los dijo alguien que habló con la verdad en el momenlo oporluno, y por lo mismo, en el momento que los hechos necesitan de la palabra; y además, lo dijo alguien que acompañó sus palabras con el teslimonio de su vida y entrega. No es que Monseñor Romero añada algo nuevo al magisterio de la Iglesia, o a Medellín en particular, sino que añade justamente lo que les falta: su aplicación a las realidades concretas. Es ahí donde el magisterio de la Iglesia se hace, empleando las mismas palabras de Monseñor Romero. "sangre y vida, verdad e historia".

Monseñor Romero fue generoso con el magisterio de la Iglesia. En sus homilías, prodiga las citas de la enseñanza de la Iglesia y en ellas este magislerio se hizo relevante y operativo; desencadenó una pastoral liberadora y ganó credibilidad para la Iglesia. Sin embargo, el magisterio de la Iglesia no ha sido muy generoso, por el momento, con el testimonio y la predicación de Monseñor Romero32. Pensamos que es hora de que el magisterio de la Iglesia en América Latina, reconozca el testimonio profético y martirial de Monseñor Romero y lo vea como un modelo de lo que la comunidad eclesial debe hacer con su magisterio.

32. Los obispos latinoamericanos con ocasión de la IV Asamblea General del Espiscopado de América Latina, en Santo Domingo, recogen el testimonio de Monseñor Romero y los mártires de la UCA, en el documento conocido como Secunda Relatio; sin embargo, esla propucsla no pasó al texto definitivo. Cfr. J. Sobrino, "Los vientos que soplaron en Santo Domingo y la evangelización de la cultura", Revista Latinoamericana de Teologia 27 (1992) pp. 276-279. 
Si hemos recordado a Medellín y a Monseñor Romero es porque creemos que ambos siguen teniendo plena vigencia en los pueblos y en la Iglesia de América Latina. Muchas cosas han cambiado en el mundo y en América Latina, pero la situación de pobreza e injusticia en que viven las mayorias populares es hoy más grave y dramática que hace treinta años. Reconocerlo debería llevamos a reconocer que Medellín y Monseñor Romero aún tienen mucho que enseñarnos. 